\title{
Electrophysiological study of the Babinski sign in paraplegic patients
}

\author{
A ROBY-BRAMI, J R GHENASSIA, B BUSSEL
}

From INSERM U215 and Service de rééducation neurologique, Hopital Raymond Poincaré, Garches, France

SUMMARY The physiopathology of the Babinski sign was investigated electrophysiologically in patients with spinal cord lesions. The stimuli were delivered via a blunt probe. The force exerted perpendicular to the plantar surface and the forward displacement of the probe were measured. The responses were recorded by surface electromyography of the Extensor Digitorum Longus and Flexor Hallucis Brevis. The latencies of the responses were 160-500 ms. The shortest latencies were observed after strong and fast-increase, moving or static stimuli. The responses to weak, gradual stimulation, appeared at a constant delay after the start of the displacement, equal to the minimum latency. An earlier phasic response was observed after fast-increase stimulations in two subjects. The long latency of the responses is probably due to a long central delay, similar to the late flexion reflex following electrical stimulation.

Since its original description in 1896,' the Babinski sign has been widely used in clinical neurology and its underlying pathophysiology has been the subject of considerable debate. ${ }^{2-7}$ It is usually agreed that it is part of the general flexion reflex released by a pyramidal lesion ${ }^{37}$ The normal plantar reflex is either described as a "private" purely cutaneous reflex ${ }^{27}$ or as the extensor component of a coordinated withdrawal from a nociceptive stimulus. ${ }^{89}$

We recently demonstrated ${ }^{10}$ that the flexion reflexes that are induced by electrical stimulation of the peripheral nerves of patients with a complete spinal cord section could be separated into two distinct reflexes with latencies of approximately $100 \mathrm{~ms}$ and between 130 and $400 \mathrm{~ms}$, respectively. The early reflex was similar to the flexion reflex of normal subjects, ${ }^{11}$ and corresponded to the nociceptive flexion reflex of spinal-sectioned animals. ${ }^{12}{ }^{13}$ We showed ${ }^{10}$ that the late reflex had its own pathway, with a central conduction time of at least $100 \mathrm{~ms}$, and was similar to the late flexion reflex found in DOPA treated acute spinalsectioned cats. ${ }^{14}$

This study was undertaken to determine whether the Babinski sign is an "early" or a "late" flexion reflex. Therefore, we investigated the latency of the flexion

Correspondence to: Dr A Roby-Brami, INSERM U215, Hopital Raymond Poincaré, 92380, Garches, France.

Received 7 February and in revised form 31 May 1989. Accepted 5 July 1989 reflex resulting from natural mechanical stimu similar to those used in clinical neurology.

The action of toe extensor muscles is, physio logically, a flexion movement since it leads to shortening of the limb; $;^{12}$ conversely, the action of the toe flexors leads to a lengthening of the limb. In this paper, the terms "flexion" and "extension" are used the physiological sense.

\section{Methods}

Patients

Nine patients (three women and six men, aged 18-45), all with a clear Babinski sign, participated in this study. They were inpatients at the rehabilitation centre and had volunteered to take part after being informed of the experimental aim of the study. All had paraplegia due to indirect spinal cord trauma which had induced a clinically complete section of the cord in four cases. The lesion levels were from D8 to $\mathrm{C} 7$, and the time between the initial trauma and the date of the examination was between two months and three years. We considered the spinal lesion to be complete in four cases, since the patients were incapable of any voluntary movement below the level of the lesion and had total sensory loss. Two patients with incomplete lesions had a moderate injury and were able to walk with a support; they could voluntarily flex their ankles and their plantar sensitivity was abnormal but present. The remaining three patients had severe cord injuries; they had minimal residual voluntary movements and sensitivity. All the selected patients had readily elicited flexion reflexes and brisk tendon jerks. Patients with uncontrollable flexor spasms were not included in this study. 
The patients were free from any medical complications of paraplegia at the time of the examination.

\section{Stimulation}

Stimuli were administered via a blunt steel probe screwed to a force transducer. For mechanical stimulation the experimental apparatus comprised a wooden frame and a sliding chariot (fig la). The force transducer was placed in the chariot and inserted into a cylindrical well perpendicular to the plane of the frame. The stretch of the transducer was maintained by a spring with a force of $20 \mathrm{~N}$. Rotation movements were prevented by a stop. The nylon wheels of the chariot containing the force transducer were placed in two aluminium rails to allow movements along the main axis of the frame. The wire of a displacement transducer was fastened to the sliding chariot to measure the force exerted perpendicular to the plane of the frame and the longitudinal displacement of the probe.

The patient sat in his/her wheel chair during the recording session. The frame was then placed obliquely in front of the patient. An examiner supported the limb at the knee and the ankle, with the foot passively extended. The frame was positioned parallel, $1 \mathrm{~cm}$ from the sole, with the lateral plantar border in front of the probe. A second researcher performed the stimulation with the probe. The effects of the two types of stimuli were compared. Moving stimuli were designed to simulate the clinical procedures used to test the Babinski sign: the probe was moved along the lateral plantar border towards the toes. ${ }^{15}$ Static stimuli consisted of firm steady pressures to the medial third of the lateral plantar border. Twenty to 50 moving and static stimuli of varying force and duration were applied in each session. The maximum stimulation time was 1 to $2 \mathrm{~s}$ and at least $8 \mathrm{~s}$ separated the stimuli. Care was taken to ensure that the limb was relaxed before each stimulation.

\section{Recording}

The most sensitive effector of the Babinski sign is the Extensor Hallucis Longus (EHL). ${ }^{316}$ The EHL muscle is a deep muscle covered by the Extensor Digitorum Longus (EDL) and the Tibialis Anterior (TA) muscles which usually fire together with the EHL. As the lack of selectivity was not a problem in patients with a clear Babinski sign, muscular activity was recorded by surface electromyography (EMG). The recording surface electrodes were placed above the belly of the EDL, at the middle third of the leg, just external to the tibial crest. The Flexor Hallucis Brevis (FHB), the effector of the normal plantar reflex, was also recorded by surface EMG using electrodes placed at the medial part of the plantar arch.

\section{Analysis of the results}

The force output signal was used as a synchronisation signal indicating experimental pressure on the transducer. The EMG traces and the bio-mechanical signals were displayed on an oscilloscope and recorded for further analysis using an analog-digital converter linked to an Apple II microcomputer. The signals were digitalised at $1000 \mathrm{~Hz}$ for $1500 \mathrm{~ms}$ after the trigger and stored on disc. The following values were obtained (fig 1b): Stimulation initiation and stimulation termination. The maximum force (F max) and its time ( $\mathrm{T}$ max) after stimulation initiation, the force-time slope was calculated (Fmax/Tmax). The delay between the stimu-
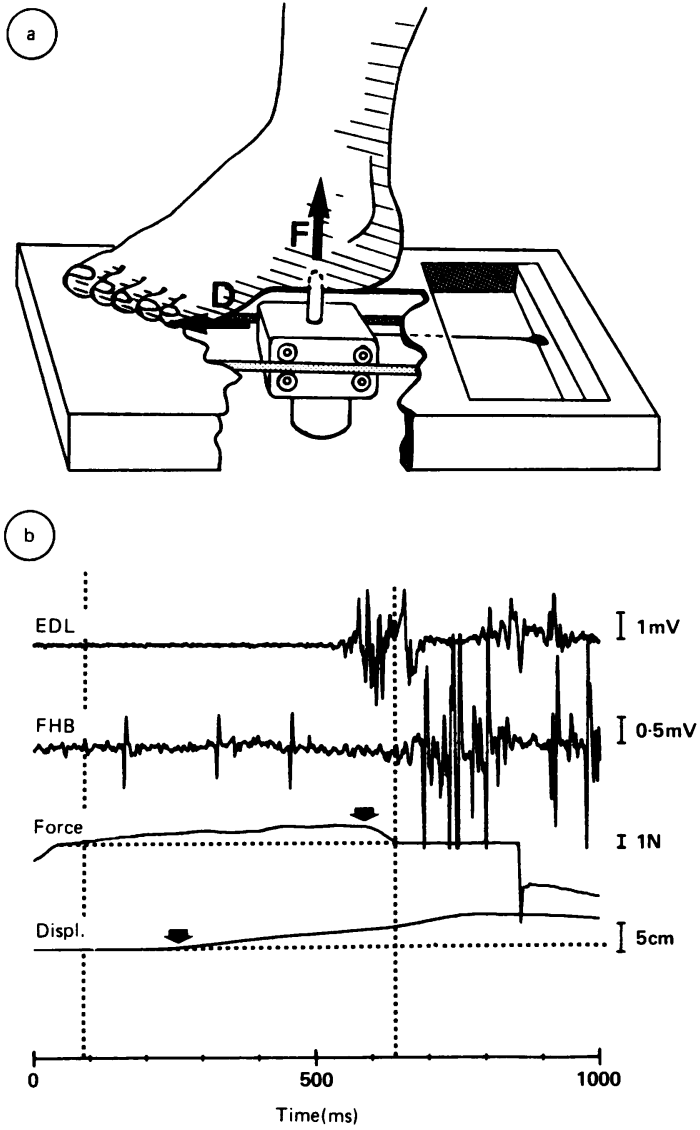

Fig 1 (a) Experimental system. (b) Typical recording. From top to bottom: EMG of the Extensor Digitorum Longum (EDL) muscle, EMG of the Flexor Hallucis Brevis $(F H B)$, stimulation force, probe displacement. The dotted horizontal lines indicate the baseline for the mechanical recordings. The vertical stippled lines indicate the beginning and the end of stimulation (Note: the force transducer is stretched between stimulations so that the force signal is negative). Calibration bars are on the right of the traces and the time scale is at the bottom of the figure.

lation initiation and the start of displacement (displacement time, DT). The total displacement during stimulation and its velocity. The latencies of the first EMG bursts of the EDL and FHB muscles.

\section{Results}

\section{Stimulation analysis}

It should be emphasised that in this study the stimulation resulted from an interaction between the gesture of the examiner and the reaction of the patient's foot. The change in force during stimulation depended on 
the shape of the plantar surface, passive movements and active withdrawal of the foot. Thus analysis of the stimulation parameters is an integral part of the results.

In most cases, as shown in fig $1 \mathrm{~b}$, probe displacement began after the onset of the stimulation (that is, the DT value was greater than zero). The force increased continuously until it reached Fmax at Tmax. The stimulation could sometimes be separated into several phases of ascending, "plateau" and descending force changes. The forces, times of onset and slopes of these phases were measured in a preliminary study. These values provided no additional information on the stimulus-response relationship than the Fmax, Tmax and DT values and are therefore not included.

The stimulation parameters were not independent of each other. Strong stimuli appeared to have fastincrease forces, high displacement velocities and short delays between stimulation initiation and the start of the probe displacement. Care was taken to deliver a variety of stimuli, for example, strong and slow stimuli.

The range of stimuli delivered during each experimental session was roughly similar for all subjects and varied within the limits shown in table 1. Most of these stimuli had no nociceptive character and we verified that they were not felt as painful by normal subjects.

\section{EDL response threshold}

In most of the experiments with moving stimuli, an EDL muscle response occurred after all stimuli indicating that the force threshold was lower than the minimal force of the stimulation (1-2 N). In three subjects with a complete spinal cord section EDL responses only appeared if stimuli were stronger than a force threshold of 3-6 N. Stimuli inducing a response were also characterised by a force-time slope steeper than 10-20 N/s. In experiments with static stimuli, a force threshold could be determined in all except two patients. It was higher (4-12 N) than the threshold of moving stimuli in all these patients. In the two other patients, both with incomplete spinal lesions, all the static stimuli induced a response. Even when it was high enough to be measured, the force threshold observed in the patients with incomplete lesions (4-8 $\mathrm{N})$ remained lower than the threshold of the patients with complete sections $(5-12 \mathrm{~N})$.

Table 1 Stimulation force and duration (see text for abbreviations)

\begin{tabular}{lcc}
\hline & Moving stimuli & Static stimuli \\
\hline F max & $1-15 \mathrm{~N}$ & $2-20 \mathrm{~N}$ \\
T max & $30-750 \mathrm{~ms}$ & $30-750 \mathrm{~ms}$ \\
Slope & $5-150 \mathrm{~N} / \mathrm{s}$ & $5-150 \mathrm{~N} / \mathrm{s}$ \\
DT & $0-350 \mathrm{~ms}$ & \\
D max & $0.03-0.15 \mathrm{~m}$ & \\
\hline
\end{tabular}

Latency of the EDL response

The latency of the EDL response varied widely from one stimulation to the other (from 160 to $500 \mathrm{~ms}$ in most of the subjects) and was systematically studied as a function of the biomechanical parameters of the stimulation. Figure 2 shows the results obtained in one representative subject. The minimum latency of the EDL response was observed after strong stimuli (figs 2a-b) with a high force-time slope (figs $2 \mathrm{c}-\mathrm{d}$ ). There was a significant inverse correlation between the EDL response latency and the Fmax value for moving stimuli (fig 2a, $r=-0.391, p<0.01$ ) and for static stimuli (fig $2 b, r=-0.411, p<0.01$ ). The EDL response latency decreased to a minimum when the slope of moving (fig 2c) or static (fig 2d) stimuli were increased and kept constant for steeper stimuli. The minimum EDL response latency was the same for both kinds of stimuli. However, the force-time slope required to reach minimum EDL response latency with static stimuli was approximately double that required for moving stimuli. Similar results were obtained with all the subjects.

There was a correlation between the latency of the EDL response and the time of the maximum force Tmax for both moving (fig 2e, r = 0.688, p < 0.01年 $\vec{\omega}$ and static stimulations (fig $2 \mathrm{f}, \mathrm{r}=0.877, \mathrm{p}<0.01$ ) There were similar results in six other subjects. Tmå 응 regularly followed the EDL response and was prob@ ably determined by the response itself, the limb withdrawal inducing a drop in the force applied through the probe.

The EDL response appeared to follow the start of the probe displacement by a fixed interval (fig 3a). The EDL response latency varied linearly with probe displacement delay DT (fig 3b). The slope of the regression line was near 1 , indicating that the interval between the start of displacement and the EDL response was constant. The minimum response latency occurred when the stimuli moved immediately and was evaluated by the point of origin of the regression line. Similar results were obtained in all the subjects (table 2). The slopes of the regression line do not differ from one in five subjects. In eight subjects the average minimum EDL response latency was $160 \mathrm{~ms}(102-235 \mathrm{~ms})$.

The latency of the EDL response was not dependent on the total displacement of the probe during stimulation. The relationship of the EDL response latency with the velocity of the probe displacement was similar to the one with the force-time slope since the steepest stimuli were also the fastest.

The latency of the EDL response and its relationship to the stimulation parameters were the same in patients with a complete and incomplete spinal cord lesions (table 2).

Thus, EDL responses with a prolonged latency 


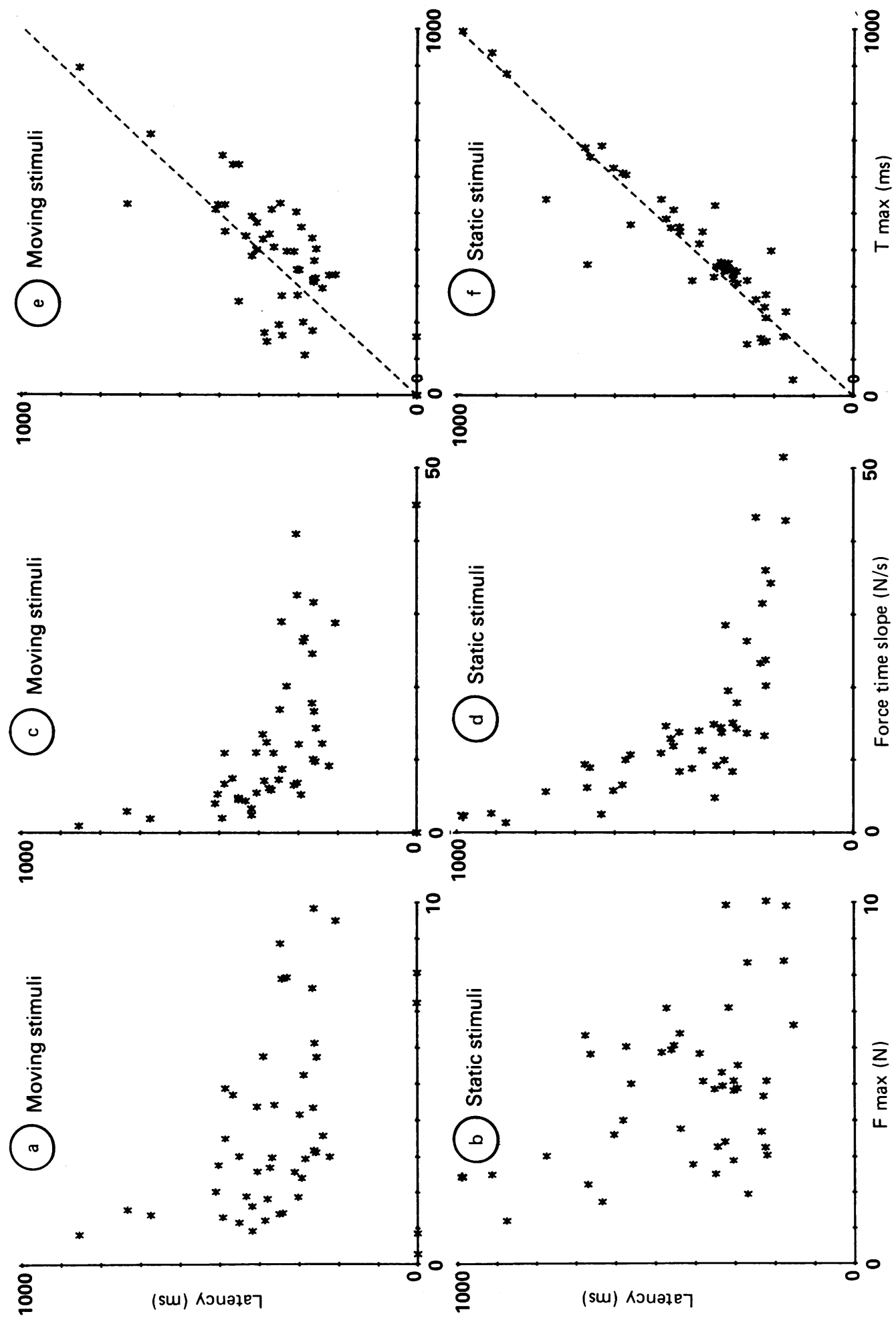

Fig 2 Latency of the EDL response as a function of the stimulation parameters. Each point represents one stimulation. $A-B$ : Latency of the EDL response as a function of the maximum force attained during stimulation (Fmax). C-D: Latency of the $E D L$ response as a function of the force-time slope (Fmax/Tmax). E-F: Latency of the EDL response as a function of the time of the Fmax, maximum value of the force (Tmax). The bissecting line is indicated (stippled). A-C-E: moving stimuli, $B-D-F$ :static stimuli. 


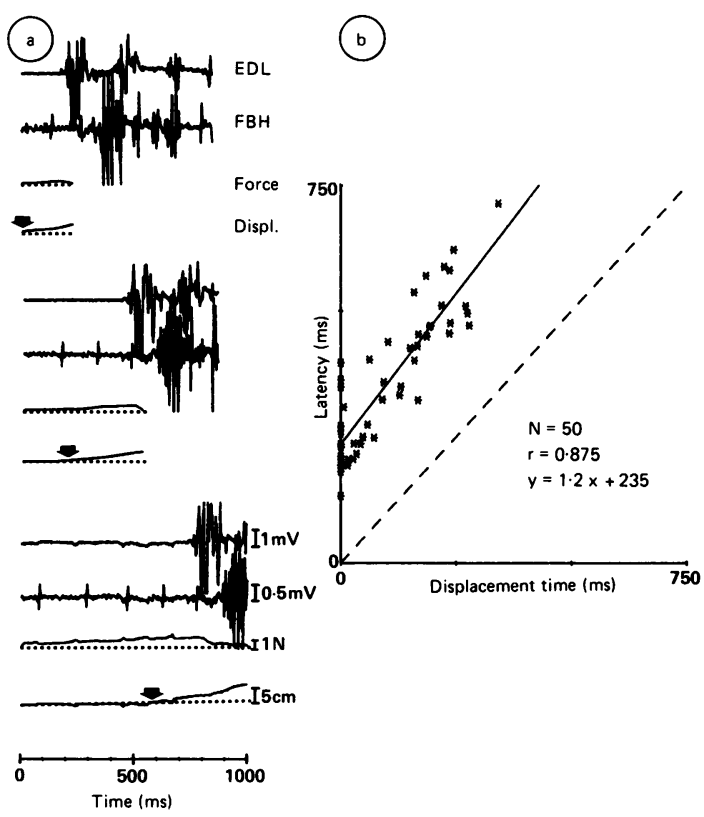

Fig 3 Latency of the EDL response for different delays in probe displacement (DT). (a) Recordings for three increasing $D T$ values. Legend as in figure $1 b$. The arrows indicate the start of the probe displacement. (b) Latency of the EDL response as a function of DT. Each point represents one stimulation. The continuous line represents the regression line, its numerical values are indicated in the lower right corner. Its slope is near 1, that is, it is roughly parallel to the bissecting line (stippled), indicating that the interval between the start of displacement and the response is constant.

occurred after weak, slow and slow-increase stimuli and were triggered by the start of the probe displacement. EDL response minimum latency (mean $160 \mathrm{~ms}$ ) was observed after strong, fast and fastincrease, moving or static stimuli.

\section{EDL response pattern}

The EDL response was either prolonged and tonic or composed of several regular $100 \mathrm{~ms}$ bursts. There was no significant relationship between the stimulation force and the size of the response, measured by integrating the EMG during the burst.

\section{$F H B$ response}

A precise quantitative study of the FHB response could not be performed in most of the patients, since they usually had a slight, but uncontrollable, tonic FHB activity (fig $1 \mathrm{~b}$ ) and the stimulation itself frequently induced skin deformation artifacts.

A FHB response occurred regularly approximately $100-150 \mathrm{~ms}$ after the onset of the EDL response and frequently alternated between EDL bursts (fig 1b, 3a). Its threshold was similar to that of the EDL response. Any tonic FHB activity could be suppressed during the first EDL burst (fig lb).

An additional earlier response, with a latency of approximately $80-90 \mathrm{~ms}$, was shown in two subjects who had an incomplete lesion. This response appeared as a phasic short-duration burst after strong and fastincrease static stimuli (fig 4a, 4c). Later responses in both the FHB and EDL muscles were similar to those of the other patients. They were induced by more prolonged stimuli (fig $4 \mathrm{~b}$ ), independently from the early FHB response (compare figs $4 \mathrm{~b}$ and $4 \mathrm{c}$ ).

\section{Discussion}

\section{Comparison with clinical studies}

In this study, the EDL responses corresponding to the Babinski sign were more easily obtained (more frequently and with a lower threshold) after moving than after static stimuli. Moreover, they were triggered by the start of the probe displacement. In most of the patients, the force threshold for moving stimuli was lower than the weakest stimuli delivered in the conditions of our work. This is consistent with the results of several clinical studies in which the optimal stimulus

Table 2 Relationship between the latency of the EDL response and the interval between the beginning of stimulation and the start of the probe displacement. N: Number of stimuli. Nature of the spinal lesion. IM: incomplete moderate lesion. IS: incomplete severe lesion. C: complete lesion. A: slope of the regression line. B: point of origin of the regression line, evaluating the minimum latency of the EDL response. $r$ : correlation coefficient. p1: correlation significance. p2: degree of significance of the difference from 1 for the slope of the regression line

\begin{tabular}{|c|c|c|c|c|c|c|c|}
\hline Patients & Lesion & $N$ & $A$ & $B$ & $r$ & $p l$ & $p^{2}$ \\
\hline $\begin{array}{l}\text { Cat } \\
\text { Hec } \\
\text { Del } \\
\text { Lau } \\
\text { Syl } \\
\text { Thi } \\
\text { Yol } \\
\text { Tah } \\
\text { Car }\end{array}$ & $\begin{array}{l}\text { IM } \\
\text { IM } \\
\text { IS } \\
\text { IS } \\
\text { IS } \\
\text { C } \\
\text { C } \\
\text { C } \\
\text { C }\end{array}$ & $\begin{array}{l}17 \\
33 \\
38 \\
43 \\
50 \\
67 \\
33 \\
32 \\
25\end{array}$ & $\begin{array}{l}0.95 \\
0.69 \\
0.78 \\
0.98 \\
1.2 \\
1.24 \\
1.25 \\
1.23 \\
0.46\end{array}$ & $\begin{array}{l}120 \\
226 \\
140 \\
148 \\
235 \\
102 \\
197 \\
117 \\
413\end{array}$ & $\begin{array}{l}0.678 \\
0.75 \\
0.819 \\
0.735 \\
0.875 \\
0.676 \\
0.77 \\
0.84 \\
0.457\end{array}$ & $\begin{array}{l}<0.001 \\
<0.001 \\
<0.001 \\
<0.001 \\
<0.001 \\
<0.001 \\
<0.001 \\
<0.001 \\
<0.02\end{array}$ & $\begin{array}{l}\text { NS } \\
<0.01 \\
<0.02 \\
\text { NS } \\
<0.01 \\
\text { NS } \\
\text { NS } \\
\text { NS } \\
<0.01\end{array}$ \\
\hline
\end{tabular}


a

EDL

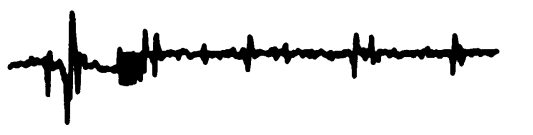

FHB

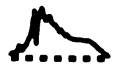

Force
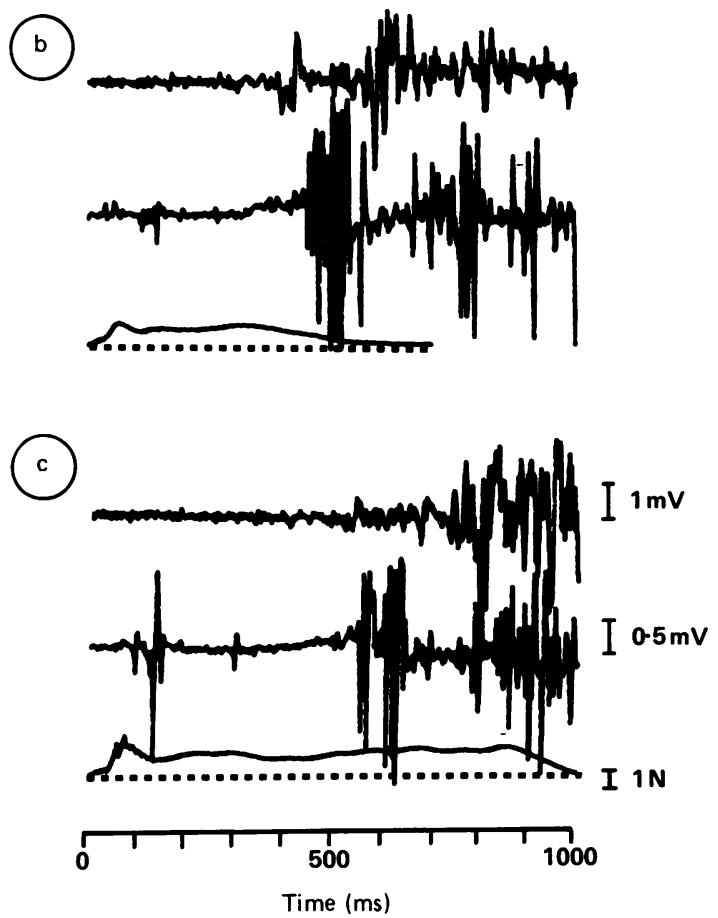

Fig 4 Responses of the FHB to static stimulation. Examples of recordings obtained with different kinds of stimulation.

Legend as in fig $1 b$. (a) Short duration, fast-increase stimulation inducing a response with a $90 \mathrm{~ms}$ latency in the $F H B$ muscle. (b) Long duration stimulation inducing later responses in the EDL and $F H B$ muscles. (c) Long duration stimulation, with a brisk onset, inducing both an early $F H B$ and later $E D L$ and $F H B$ responses.

was found to be a scratch or a moving pressure. ${ }^{31517}$ Although stimuli inducing a Babinski response are frequently described as nociceptive, ${ }^{37}$ our data confirm the previous observations of $\mathrm{Kuhn}^{18}$ and Marshall ${ }^{19}$ that the Babinski sign may occur after clearly non-nociceptive stimuli.

\section{Nature of the responses}

All the responses in the four patients with a complete spinal cord section were generated at the spinal level but the participation of supraspinal structures cannot be excluded in patients with incomplete spinal cord lesions. However, such participation is unlikely. The responses had the same latency in the two groups of patients and the relationship between the stimulation parameters and the response latencies were also the same. The only difference was that the response threshold was usually lower in the patients with incomplete lesions. This suggests that the reflex pathways are more excitable in the patients with incomplete lesions and not that the pathways are different.

The 80-90 ms latency response of the FHB (fig 4) is similar to the plantar reflex described by Engberg ${ }^{20}$ in the acute spinal cat as a brisk extension of the toes elicited by a tap on the plantar cushion. It was subsequently shown ${ }^{21}$ that the plantar cushion reflex was linked to the activation of an oligosynaptic pathway excited by cutaneous afferents in the $A \alpha$ range. In our study, the conduction velocity of the afferents mediating this response is within the $A \alpha$ range $(30-50 \mathrm{~m} / \mathrm{s})$ given the distance from the foot to the spinal level $\mathrm{S} 1$ (more than $1.4 \mathrm{~m}$ ) and the conduction velocity of $\alpha$ motor axons $(30-50 \mathrm{~m} / \mathrm{s})$. Cutaneous fast conducting afferents are known to correspond to tactile units. ${ }^{22}$ The early response appears only after strong and fast-increase stimuli, probably because it requires the spatial summation of the synchronised discharge of many low threshold receptors. This is consistent with the observation that the discharge of the tactile mecanoreceptors in the foot pad of the cat $^{23}$ and of the human hand ${ }^{24}$ may both be time locked to the onset of the stimulation if the slope of the skin indentation is steep. Although the toe movement was not recorded, this reflex probably accounts for the brief toe plantar flexion which may preceed the Babinski sign in some patients. ${ }^{3}$

The main responses appeared with a prolonged latency $(160-500 \mathrm{~ms})$ in both muscles. This is consistent with the results obtained by others who noted that the plantar reflexes appeared a few hundred $\mathrm{ms}$ after the onset of mechanical stimulation. ${ }^{31625}$ In our patients with an evident Babinski sign, all the plantar stimuli induced a dorsal flexion of the toe, so our study cannot show differences between the normal plantar reflex and the Babinski sign. Landau and Clare ${ }^{3}$ observed a simultaneous activation of both the EDL and the FHB muscles in normal subjects as well as in patients with pyramidal lesions. They showed that the Babinski sign is due to the dominance of the contraction of the EDL and EHL muscles. Similar results were observed after electrical stimulations. ${ }^{31626}$

In our study, the Babinski sign may be assimilated to the EDL response. The precise measure of the EDL response latency and the analysis of the mechanical stimulation provides further opportunity for discus- 
sion. Its long latency may be due to a long central delay, as is the latency of the late flexion reflex following electrical stimulation. ${ }^{10}$ It could also be due to the recruitment of slowly-conducting afferents and/or the desynchronisation of the afferent volley.

The stimulation used may be capable of exciting all types of cutaneous and subcutaneous mechanoreceptors. ${ }^{22}$ The tactile afferent units with conduction velocities in the $A \alpha$ range $^{27}$ were undoubtedly always stimulated. The strongest stimuli may excite nociceptors which are linked to myelinated $\mathrm{A} \delta$ and nonmyelinated slowly conducting $C$ afferents. Some low threshold mechanoreceptors have been linked to slowly conducting afferents in the $A \delta^{28}$ and $\mathrm{C}^{29}$ range. The non-myelinated $\mathrm{C}$ afferents cannot be involved in the response recorded within $1000 \mathrm{~ms}$ after the onset of the stimulation, because of the length of the afferent pathway in humans. Kugelberg ${ }^{25}$ described a reflex transmitted by non-myelinated afferents in patients with a Babinski sign, but this reflex was obtained by a different mechanical stimulation (stroking with a needle or heat) and had a latency between 1300 and $2300 \mathrm{~ms}$.

The late EDL and FHB responses clearly require a great range of spatial and temporal summation (fig 4). The receptors involved in these responses may be some tactile units in the $A \alpha$ range or mechanoreceptors in the $A \delta$ range. ${ }^{28}$ Summation mechanisms could explain why the latency of the responses decreased as the force of the stimulation or its slope increased. However, summation mechanisms do not explain why the EDL response is triggered by the start of the probe displacement after a fixed delay equal to the minimum latency of the response and why this minimum is the same after static stimuli. The minimum response latencies varied from one subject to another. Thus, it is very unlikely that the start of probe displacement acted via the excitation of a particular kind of receptor.

The late EDL response is therefore probably a late flexion reflex similar to that found in paraplegic patients after distal electrical stimulation. ${ }^{1026} \mathrm{We}$ demonstrated $^{10}$ that this reflex had a long central conduction time (of at least $100 \mathrm{~ms}$ ) and a low threshold, corresponding to fast conducting afferents. Its main feature was that its latency increased with the intensity or duration of stimulation. This property enabled us to compare the late flexion reflex in paraplegic patients with that observed in the DOPAtreated acute spinal cat. ${ }^{14}$ As proposed by Lundberg $e t$ $a l,{ }^{30}{ }^{31}$ the variations in the late reflex latency could be due to a convergence of long latency excitatory and short latency inhibitory pathways excited by the same afferents on flexor motor neurons. Animal experiments $^{3233}$ have shown that the late flexion reflex is related to the pathways subserving spinal stepping.
This hypothesis was formulated by Pierre Marie and Foix ${ }^{4}$ at the conclusion of their pioneering work which compared their clinical observations with Sherrington's work" on spinal stepping. "Le reflexe de Babinski appartient au même ordre de mouvements automatiques que le réflexe des racourcisseurs, c'est à dire en dernière analyse à un automatisme de marche."*

We are grateful to the patients who took part in this study, B Guezard for his technical assistance, and to O Parkes for correcting the English.

\section{References}

1 Babinski J. Sur le reflexe cutané plantaire dans certaines affections organiques du système nerveux central. $C R$ Soc Biol (Paris) 1896;48:207-8.

2 Déjerine J. Séméiologie des réflexes. In: Séméiologie des affections du système nerveux. Paris: Masson, 1926.

3 Landau WM, Clare MH. The plantar reflex in man, with special reference to some conditions where the extensor response is unexpectedly absent. Brain 1959;82:321-55.

4 Marie P, Foix Ch. Les reflexes d'automatisme medullaire et le phénomène des racourcisseurs. Leur valeur séméiologique, leur signification physiologique. J Neurol 1912;10:657-76.

5 Nathan PW, Smith MC. The Babinski response: a review and new observations. Brain 1955;18:250-9.

6 Van Gijn J. The Babinski sign and the pyramidal syndrome. Neurol Neurosurg Psychiatry 1978;41:865-73.

7 Walshe F. The Babinski plantar response, its form and it physiological and pathological significance. Brain 1956;790 529-56.

8 Grimby L. Pathological plantar response: disturbances of the normal integration of flexor and extensor reflex components. $\delta$ Neurol Neurosurg Psychiatry 1963;26:314-21.

9 Kugelberg E, Eklund E, Grimby L. An electromyographic stud of the nociceptive reflexes of the lower limb. Mechanism of the plantar responses. Brain 1960;83:394-410.

10 Roby-Brami A, Bussel B. Long latency spinal reflex in man after flexor reflex afferent stimulation. Brain 1987;110:707-25.

11 Hugon M. Réflexes polysynaptiques et commandes volontaires. Contribution à la connaissance de l'organisation nerveuse spinale de l'animal et de l'homme. Thèse de sciences naturelles, Paris, 1967.

12 Sherrington CS. Flexion reflex of the limb, crossed extension reflex and reflex stepping and standing. J Physiol (London) 1910;40: 28-121.

13 Lloyd DPC. Neuron patterns controlling transmission of ipsilateral hind limb reflexes in cat. $J$ Neurophysiol 1943;6:293-315.

14 Anden NE, Jukes MGM, Lundberg A, Vycklicky L. A new spinal flexor reflex. Nature 1964;202:1344-5.

15 Dohrmann GJ, Nowack WJ. The upgoing great toe: optimal method of elicitation. Lancet 1973;i:399-444.

16 Van Gijn J. Babinski response: stimulus and effector. $J$ Neurol Neurosurg Psychiatry 1975;38:180-6.

17 Riddoch $\mathrm{G}$. The reflex functions of the completely divided spinal cord in man, compared with those associated with less severe lesions. Brain 1917;40:264-402.

18 Kuhn RA. Functional capacity of the isolated human spinal cord. Brain 1950;73:1-51.

19 Marshall J. Observations on reflex changes in the lower limbs in

*"The Babinski sign belongs to the same kind of automatic movements as the shortening (flexion) reflex and thus to a stepping automatism." 

spastic paraplegia in man. Brain 1954;77:290-304.

20 Engberg I. Reflexes to foot muscles in the cat. Acta Physiol Scand 1964;62, S236:1-64.

21 Egger MD, Wall PD. The plantar cushion reflex circuit: an oligosynaptic cutaneous reflex. J Physiol (London) 1971;216: 483-501.

22 Iggo A. Cutaneous receptors. In: Hubbard JI, ed. The peripheral nervous system. New York: Plenum, 1974:347-404.

23 Iggo A, Ogawa $\mathrm{H}$. Correlative physiological and morphological studies of rapidly adapting mechanoreceptors in cat's glabrous skin. J Physiol (London) 1977;277:275-96.

24 Knibestol M. Stimulus-response functions of rapidly adapting mechanoreceptors in the human glabrous skin area. J Physiol (London) 1973;232:427-52.

25 Kugelberg E. Demonstration of $A$ and $C$ fibre component in the Babinski plantar response and the pathological flexion reflex. Brain 1948;71:304-19.

26 Grimby L. Pathological plantar response. Part I Flexor and extensor components in early and late reflex parts. $J$ Neurol Neurosurg Psychiatry 1965;28:469-75.

27 Vallbo AB, Johansson RS. Properties of cutaneous mechano- receptors in the human hand related to touch sensation. Human Neurobiol 1984;3:3-14.

28 Adriaensen H, Gybels J, Handwerker HO, Van Hees J. Responses properties of thin myelinated $(\mathbf{A} \delta$ ) fibers in human skin nerves. $J$ Neurophysiol 1983;49:111-22.

29 Bessou P, Burgess PR, Perl ER, Taylor CB. Dynamic properties of mechanoreceptors with unmyelinated (C) fibers. J Neurophysiol 1971;34:116-31.

30 Jankowska E, Jukes MGM, Lund S, Lundberg A. The effect of DOPA on the spinal cord. 5- Reciprocal organization of pathways transmitting excitatory action to alpha motoneurones of flexor and extensors. Acta Physiol Scand 1967;70:369-88.

31 Lundberg A. Multisensory control of spinal reflex pathways. Progress in Brain Research 1979;50:11-28.

32 Jankowska E, Jukes MGM, Lund S, Lundberg A. The effects of DOPA on the spinal cord. 6- Half centre organization of interneurons transmitting effects from the flexor reflex afferents. Acta Physiol Scand 1967;70:389-402.

33 Viala D, Valin A, Buser P. Relationship between the "late reflex discharge' and locomotor movements in acute spinal cats and rabbits treated with DOPA. Arch Ital Biol 1974;112:229-306. 